\title{
Faktor yang Memengaruhi Asertivitas Perempuan di Kabupaten Nias
}

\author{
Eustalia Wigunawati \\ Universitas Kristen Indonesia
}

\begin{abstract}
Abstrak: Masyarakat Kabupaten Nias merupakan penganut budaya patriarki. Perempuan masih dianggap sebagai pelengkap bagi laki-laki dan bukan individu yang berdaya. Kondisi ini membuat perempuan rentan mengalami kekerasan. Kekerasan yang dialami perempuan menggambarkan seorang yang tidak memiliki asertivitas. Asertivitas penting dimiliki oleh perempuan dalam menghadapi banyak situasi yang kurang menguntungkan. Apa yang menyebabkan perempuan di Nias kurang memiliki asertivitas? Artikel ini mencoba menguraikan faktor-faktor yang mempengaruhi asertivitas perempuan di Kabupaten Nias. Adapun faktor yang mempengaruhi asertivitas antara lain jenis kelamin, budaya, pendidikan, situasi tertentu yang dialami, dan harga diri. Adapun tujuan dari artikel ini adalah untuk mengetahui gambaran mengenai faktor-faktor yang memengaruhi asertivitas perempuan di Nias. Harapannya, kajian ini dapat menjadi langkah awal dalam melakukan intervensi untuk meningkatkan asertivitas perempuan di Nias.
\end{abstract}

Kata Kunci: Asertivitas, Perempuan, Nias, Patriarki

\begin{abstract}
:
Key Words: The Nias District community is a follower of patriarchal culture. Women are still considered to be complementary to men and not empowered individuals. This condition makes women vulnerable to violence. Violence experienced by women describes a person who does not have assertiveness. Asertivity is important for women to face in many disadvantaged situations. What causes women in Nias District to have low assertiveness? This article tries to describe the factors that influence women's assertiveness in Nias District. The factors that influence assertiveness include gender, culture, education, certain situations experienced, and self-esteem. The purpose of this article is to find out an overview of the factors that influence women's assertiveness in Nias District. The hope, this study can be the first step in intervening to improve women's assertiveness in Nias.
\end{abstract}

Key words: Asertivity, Women, Nias, Patriarchal

Koresponden penulis:

Eustalia Wigunawati, Program Studi Bimbingan dan Konseling Universitas Kristen

Indonesia

Jl. Mayjen Sutoyo No. 2, Cawang, Jakarta Timur.

E-mail: eustalia.wigunawati@uki.ac.id

PENDAHULUAN 
Artikel ini merupakan hasil ketertarikan penulis terhadap penelitian mengenai “Mapping Interpersonal Violence Against Women In The District Of Nias, 2009-2016" oleh Yesyca, Lase, dan Anggraini (2018). Penulis merasa tertarik apa yang melandasi perempuan di Kabupaten Nias mengalami kekerasan. Masyarakat di Kabupaten Nias merupakan masyarakat yang menganut budaya patriarki. Dalam budaya patriarki di Kabupaten Nias, laki-laki adalah pemegang kekuasaan dan kebijakan, dimana laki-laki lebih berperan dan berkuasa dibandingkan perempuan. Dengan kekuasaan yang dimiliki laki-laki, sering membuat perempuan tidak punya pilihan dalam hidupnya (Zaluchu, 2016); perempuan hanya dianggap sebagai pembantu laki-laki, pada saat menikah hanya dianggap sebagai barang belian (Zaluchu, 2015); dan tidak sedikit yang mengalami kekerasan (Anggraini, Yesyca, Lase, 2018). Secara psikologis seseorang yang mengalami kekerasan dan perlakuan yang tidak adil akan cenderung berakibat pada permasalahan kesehatan mental, seperti stres, gangguan emosi (Ziaei, et.al, 2016:1-3); depresi, dan pengalaman traumatis (Barrios, et.al, 2015:1-2). Apa yang dialami kebanyakan perempuan di Nias juga memungkinkan mereka mengalami permasalahan kesehatan mental tersebut.

Gambaran mengenai perempuan di Kabupaten Nias bertentangan dengan perilaku yang disebut dengan asertif. Walaupun laki-laki di Kabupaten Nias juga menunjukkan perilaku tidak asertif, akan tetapi kajian ini lebih berfokus pada perempuan karena perempuan di Kabupaten Nias merupakan korban dari budaya patriarki. Asertivitas diartikan sebagai perilaku yang menunjukkan kesetaraan dalam hubungannya dengan orang lain. Hubungan ini memungkinkan setiap individu dapat bertindak sesuai dengan kepentingannya sendiri, mengekspresikan perasaan dengan perasaan jujur dan nyaman, dapat membela diri tanpa merasa cemas, dan dapat menerapkan hak-hak pribadi tanpa mengabaikan hak orang lain (Alberti dan Emmons, 2002). Sedangkan menurut Towned (2007:11), asertivitas berkaitan tentang penghormatan terhadap diri sendiri dan penghormatan terhadap orang lain. Penghormatan terhadap diri sendiri melibatkan kesadaran diri, maksudnya adalah sadar mengenai siapa dirinya. Kesadaran terhadap orang lain melibatkan kesadaran mengenai siapa diri orang lain. Walaupun mereka memiliki perbedaan dengan dirinya, dalam waktu yang bersamaan tetap dapat mengekspresikan diri dan dapat bekerja sama. Seseorang yang memiliki relasi asertif adalah orang yang saling memahami satu sama lain, saling 
memahami setiap perbedaan, saling memberi dukungan, menjadi orang yang terbuka dan jujur satu sama lain. Asertivitas adalah sebuah karakteristik perilaku seseorang dalam merespon situasi dimana posisi dan minatnya akan atau dapat bertentangan dengan orang lain (Ames, 2009:112). Salah satu bentuk sikap asertif adalah kemampuan individu untuk dapat berkata "tidak" dengan tegas (Alberti dan Emmons, 2002).

Asertivitas penting dimiliki oleh perempuan di Kabupaten Nias dalam menghadapi banyak situasi yang kurang menguntungkan. Berdasarkan beberapa hasil penelitian sebelumnya menunjukkan bahwa perilaku asertif sangat penting dalam menghadapi kekerasan. Seperti penelitian yang dilakukan oleh Syafira dan Kustanti (2017:186) terhadap perempuan yang pernah mengalami kekerasan dalam pacaran. Subjek penelitian adalah tiga perempuan yang mengalami kekerasan dalam pacaran. Subjek mengalami kekerasan secara fisik, verbal, emosional dan seksual dimana dampak dari kekerasan tersebut adalah secara fisik, psikis, sosial dan seksual. Hasil penelitian pada subjek pertama menunjukkan bahwa meskipun sudah berusaha memunculkan asertivitas, akan tetapi subjek tetap merasa tidak berdaya karena kekerasan yang dialami. Bagi subjek kedua dan ketiga, asertivitas dimunculkan bertujuan agar dapat memperjuangkan diri sendiri dan hak-hak pribadinya, karena apabila asertivitas tidak dimunculkan maka pasangan akan semakin memperlakukan mereka secara tidak baik.

Penelitian lain mengenai asertivitas dilakukan oleh Novalia dan Dayakisni (2013:172). Hasil penelitian menunjukkan bahwa ada hubungan negatif yang signifikan antara perilaku asertif siswa dengan kecenderungan menjadi korban bullying. Semakin tinggi asertivitas yang dimiliki siswa maka semakin rendah kecenderungan menjadi korban bullying, begitupun sebaliknya semakin rendah asertivitas yang dimiliki siswa maka semakin tinggi kecenderungan menjadi korban bullying. Selain itu, menurut Susilawati (2016:688) dalam penelitiannya menunjukkan adanya hubungan yang negatif antara asertivitas dengan perilaku seks pranikah pada remaja yang bersekolah di SMK Negeri 5 Samarinda. Hal tersebut berarti bahwa semakin tinggi asertivitas yang dimiliki remaja maka semakin rendah perilaku seks pranikah, begitu juga sebaliknya semakin rendah asertivitas yang dimiliki remaja, maka semakin tinggi perilaku seks pranikah.

Berdasarkan penjelasan di atas menunjukkan bahwa perempuan di Kabupaten Nias sebagian besar tidak asertif. Pertanyaannya adalah, faktor apa yang menyebabkan 
perempuan di Kabupaten Nias memiliki gambaran asertivitas tersebut? Oleh karena itu, tujuan dari kajian ini adalah untuk mengetahui gambaran mengenai faktor-faktor yang mempengaruhi asertivitas perempuan di Kabupaten Nias. Harapannya adalah hasil dari kajian ini dapat menjadi langkah awal dalam melakukan intervensi untuk meningkatkan asertivitas perempuan di Kabupaten Nias.

\section{PEMBAHASAN}

Untuk dapat mengetahui penyebab perempuan di Kabupaten Nias memiliki sikap dan perilaku yang tidak menggambarkan asertivitas maka perlu diketahui faktor-faktor apa yang mempengaruhi. Seperti yang dijelaskan sebelumnya bahwa faktor-faktor yang mempengaruhi asertivitas menurut Rathus dan Nevid (1983), antara lain:

1. Jenis kelamin

Jenis kelamin yaitu laki-laki dan perempuan berpengaruh terhadap sikap asertif seseorang. Pada umumnya, laki-laki cenderung lebih asertif dibandingkan perempuan. Menurut Towned (2007:145-146), dalam konteks jenis kelamin, asertivitas sering disalahpahami dengan agresivitas. Apa yang diartikan sebagai asertif bagi laki-laki dapat dijadikan sebagai pengalaman perilaku agresif ketika diekspresikan oleh perempuan. Terdapat harapan bahwa perempuan lebih tidak langsung dalam berkomunikasi, sedangkan laki-laki lebih secara langsung. Oleh karena itu, ketika perempuan memiliki gaya komunikasi seara langsung, mereka akan dihakimi sebagai seseorang yang keluar dari jalur yang diharapkan oleh mereka. Demikian juga laki-laki yang memiliki gaya komunikasi secara tidak langsung dianggap sebagai seseorang yang tidak cukup memiliki kepercayaan diri.

\section{Kebudayaan}

Tuntutan lingkungan menentukan batasan-batasan perilaku masing-masing anggota masyarakat sesuai dengan usia, jenis kelamin, dan status sosial seseorang. Menurut Andayani dan Mardianto (2015:33-44) kelompok budaya yang berbeda mengajari anggotanya agar berperilaku yang berbeda pula. Kebudayaan yang diajarkan tertanam menjadi sebuah keyakinan pribadi. Keyakinan seseorang mempengaruhi cara orang tersebut untuk berperilaku dalam interaksi-interaksi sosial mereka.

\section{Tingkat pendidikan}


Pendidikan dapat mempengaruhi pola pikir dan perilaku seseorang. Semakin tinggi tingkat pendidikan seseorang maka semakin luas wawasan berpikirnya sehingga lebih terbuka terhadap banyak hal.

4. Situasi tertentu di sekitar

Kondisi dan situasi yang dihadapi seseorang dapat mempengaruhi keputusankeputusan yang diambil. Seperti misalnya sikap bawahan terhadap atasannya, akan berbeda sikap seseorang terhadap orang yang dianggap setara dengannya.

5. Harga diri

Seseorang yang memiliki harga diri yang tinggi cenderung memiliki kemampuan untuk menyesuaikan diri dengan lingkungan, selain itu memiliki kekawatiran sosial yang rendah mampu mengungkapkan pendapat dan perasaan tanpa merugikan diri sendiri maupun orang lain. Seperti penelitian yang telah dilakukan oleh Firdaus (2015:21) menunjukkan bahwa terdapat hubungan yang signifikan antara harga diri dengan perilaku asertif pada mahasiswa.

Berdasarkan kelima faktor tersebut, jelas faktor pendidikan adalah faktor yang sangat berpengaruh terhadap asertivitas perempuan di Kabupaten Nias. Banyak perempuan di Kabupaten Nias kurang beruntung karena tidak mendapatkan pendidikan tinggi bahkan ada yang tidak bersekolah lagi. Penggambaran pendidikan rendah, tidak hanya ditemui di Kabupaten Nias saja, melainkan juga dapat ditemui di Kabupaten lainnya di pulau Nias. Hal tersebut dapat dilihat dari tabel 1, 2 dan 3 dari Badan Pusat Statistik di Nias mengenai persentase penduduk berumur 7 sampai 24 tahun menurut karakteristik status pendidikannya pada tahun 2018.

Tabel 1. Persentase Penduduk Berumur 7-24 Tahun menurut Karakteristik dan Status Pendidikan di Kabupaten Nias, 2018

\begin{tabular}{|c|c|c|c|c|c|c|}
\hline \multirow[t]{2}{*}{ Karakteristik } & \multirow{2}{*}{$\begin{array}{l}\text { Tidak/belu } \\
\text { m pernah } \\
\text { bersekolah }\end{array}$} & \multicolumn{3}{|c|}{ Masih Bersekolah } & \multirow{2}{*}{$\begin{array}{l}\text { Tidak } \\
\text { Bersekolah } \\
\text { lagi }\end{array}$} & \multirow[b]{2}{*}{ Jumlah } \\
\hline & & $\begin{array}{l}\text { SD/ } \\
\text { Sederajat }\end{array}$ & $\begin{array}{l}\text { SMP/ } \\
\text { Sederajat }\end{array}$ & $\begin{array}{l}\text { SMA/ } \\
\text { Sederajat }\end{array}$ & & \\
\hline Laki-laki & 1,16 & 45,25 & 12,99 & 15,89 & 24,71 & 100,00 \\
\hline Perempuan & 0,81 & 43,89 & 15,90 & 11,81 & 27,60 & 100,00 \\
\hline
\end{tabular}

Sumber: Statistik Kesejahteraan Rakyat Kabupaten Nias, 2018 
Tabel 2. Persentase Penduduk Berumur 7-24 Tahun menurut Karakteristik dan Status Pendidikan di Kabupaten Nias Selatan, 2018

\begin{tabular}{|c|c|c|c|c|c|c|}
\hline \multirow{2}{*}{ Karakteristik } & \multirow{2}{*}{$\begin{array}{l}\text { Tidak/belu } \\
\text { m pernah } \\
\text { bersekolah }\end{array}$} & \multicolumn{3}{|c|}{ Masih Bersekolah } & \multirow{2}{*}{$\begin{array}{l}\text { Tidak } \\
\text { Bersekolah } \\
\text { lagi }\end{array}$} & \multirow[t]{2}{*}{ Jumlah } \\
\hline & & $\begin{array}{l}\text { SD/ } \\
\text { Sederajat }\end{array}$ & $\begin{array}{l}\text { SMP/ } \\
\text { Sederajat }\end{array}$ & $\begin{array}{l}\text { SMA/ } \\
\text { Sederajat }\end{array}$ & & \\
\hline Laki-laki & 3,37 & 38,86 & 16,20 & 19,36 & 22,20 & 100,00 \\
\hline Perempuan & 4,67 & 38,14 & 16,43 & 19,54 & 21,23 & 100,00 \\
\hline
\end{tabular}

Sumber: Statistik Kesejahteraan Rakyat Kabupaten Nias Selatan, 2018

Tabel 3. Persentase Penduduk Berumur 7-24 Tahun menurut Karakteristik dan Status Pendidikan di Kabupaten Nias Utara, 2018

\begin{tabular}{llllll}
\hline \multirow{3}{*}{ Karakteristik } & $\begin{array}{l}\text { Tidak/belu } \\
\text { m pernah }\end{array}$ & \multicolumn{2}{l}{ Masih Bersekolah } & Tidak & Jumlah \\
\cline { 3 - 4 } & bersekolah & SD/ & SMP/ & SMA/ & lagi \\
& & & Sederajat & Sederajat & Sederajat
\end{tabular}

\begin{tabular}{lcccccc}
\hline Laki-laki & 1,93 & 42,19 & 16,84 & 19,68 & 19,37 & 100,00 \\
\hline Perempuan & 1,29 & 40,88 & 15,78 & 17,73 & 24,33 & 100,00
\end{tabular}

Sumber: Statistik Kesejahteraan Rakyat Kabupaten Nias Utara, 2018

Berdasarkan data tersebut menunjukkan bahwa baik laki-laki maupun perempuan memiliki tingkat pendidikan yang rendah, bahkan $27,60 \%$ perempuan di Kabupaten Nias, 21,23\% perempuan di Nias Selatan dan 24,33\% perempuan di Nias Utara tidak bersekolah lagi. Ada banyak faktor juga yang mempengaruhi perempuan di Nias tidak dapat melanjutkan sekolah ke jenjang yang lebih tinggi atau bahkan tidak bersekolah lagi. Banyak perempuan di Nias terutama di masyarakat pedesaan yang hidup tanpa pilihan dalam pendidikan. Sejak usia remaja, banyak perempuan di Nias sudah dinikahkan oleh orangtua mereka disaat mereka seharusnya masih sekolah. Pernikahan telah mengambil hak perempuan di Nias untuk mendapatkan pendidikan (Zaluchu, 2016). 
Faktor lain yang memengaruhi asertivitas, yaitu jenis kelamin dan kebudayaan merupakan faktor yang saling berkaitan. Nias merupakah salah satu daerah yang menganut budaya patriarki. Keyakinan yang dianut adalah bahwa laki-laki berperan sangat penting dan menjadi yang utama di masyarakat sedangkan perempuan cenderung berperan sebagai pembantu laki-laki (Zaluchu, 2015); menempati tempat yang paling rendah sebagai manusia, dianggap sebagai titipan di rumah orangtuanya, sebagai istri sering dianggap sebagai subordinat (Ge'e, 2017); tidak memiliki hak bicara, dalam pertemuan sosial dan kemasyarakatan, tidak memiliki peran apapun kecuali memasak dan melayani pelaksanaan pertemuan tersebut (Irmayani, Nurbani \& Bangun, 2015). Menurut Pongtuluran (2014:19-20) dalam tulisannya menyimpulkan bahwa budaya patriarki di Indonesia salah satunya di Nias, laki-laki digambarkan memiliki kekuasaan dan tanggung jawab yang seharusnya merupakan kewajiban laki-laki untuk melindungi perempuan namun sering disalah gunakan dengan alasan mengukuhkan nilai-nilai patriarki yang dominan.

Menurut Lase (2018:2), budaya patriarki di Nias membedakan peran laki-laki dan perempuan baik dalam hubungannya dengan adat maupun dalam aktivitas sehari-hari. Laki-laki diposisikan seorang kepala yang mengambil keputusan. Sedangkan perempuan adalah pembantu laki-laki yang tidak memiliki kedudukan berarti. Menurut Lase (2018: 20-22), peran laki-laki di Kabupaten Nias yang berkuasa dan dominan membuka peluang melakukan kekerasan terhadap perempuan. Terlebih bagi perempuan yang telah menikah, didorong oleh mahar atau disebut böwö yang diberikan oleh laki-laki kepada pihak perempuan. Mahar tersebut dimaknai sebagai "barang belian" atau diistilahkan "böli gana'a". Konsekuensinya, membuat laki-laki memiliki kekuasaan dan hak untuk mengontrol perempuan sebagai istrinya. Oleh karena itu, laki-laki mudah untuk mendominasi, menguasai, dan melakukan kekerasan. Dalam hal ini kekerasan yang terjadi adalah kekerasan seksual. Di sisi lain, perempuan tidak dapat melakukan perlawanan yang berarti dan tidak dapat menuntut karena adat yang sudah ada.

Pemaparan di atas mengarahkan pada faktor kelima yang mempengaruhi asertivitas perempuan di Kabupaten Nias yaitu harga diri yang rendah. Dimana mahar dalam adat Nias mengandung isu-isu ketidakadilan gender dan merendahkan harga diri perempuan di Nias. Dalam adat Nias, mahar yang berarti bahwa perempuan dianggap seperti barang belian, akibatnya laki-laki berkuasa atas diri perempuan (Lase, 2018:21). Anggapan 
bahwa perempuan sudah dibeli atas pernikahan tersebut, maka laki-laki dapat memperlakukan perempuan sekehendak hati, sehingga tidak dapat dihindari kekerasan terhadap perempuan sering terjadi.

Faktor situasi disekitar juga mempengaruhi asertivitas perempuan di Kabupaten Nias. Laki-laki sebagai pemegang kekuasaan dan kebijakan dalam budaya patriarki, pada praktiknya sering tidak adil dan bijak bagi perempuan, sedangkan perempuan tidak cukup memiliki nyali untuk menggugat budaya yang sudah mengakar dan menjadi bagian dalam kehidupan masyarakat mereka (Nurhayati, 2016). Perempuan merasa terkungkung dan tidak bisa berbuat apa-apa ketika mereka mengalami kekerasan. Kekerasan yang dialami perempuan bukan menjadi sebuah pilihan bagi mereka. Hal tersebut bisa terjadi karena norma sosial atau budaya yang terbangun pada daerah tertentu menjadikan perempuan dapat diperlakukan dengan cara kekerasan. Perempuan tidak memiliki pertimbangan untuk keluar dari situasi tersebut karena ketakutan yang realistis bahwa mereka akan dianggap menentang tradisi dan dikeluarkan dari anggota masyarakat (Guruge et.al, 2017:1-2).

Berdasarkan penjelasan mengenai faktor yang mempengaruhi asertivitas yang disampaikan oleh Rathus dan Nevid (1983), dapat disimpulkan bahwa dari kelima faktor tersebut mempengaruhi asertivitas perempuan di Kabupaten Nias. Dimana dari kelima faktor tersebut sangat berperan penting dan saling berkaitan satu dengan yang lain.

\section{KESIMPULAN}

Berdasarkan penjelasan di atas menunjukkan bahwa perempuan di Kabupaten Nias sebagian besar tidak asertif. Faktor-faktor yang mempengaruhi perempuan di Kabupaten Nias memiliki asertivitas yang rendah antara lain adalah jenis kelamin, budaya patriarki, tingkat pendidikan yang rendah, situasi dimana perempuan di Nias tidak dapat menggugat budayanya, dan perlakuan laki-laki yang merendahkan harga diri perempuan.

Faktor tingkat pendidikan yang rendah dapat dilihat dari data BPS tahun 2018 yang menunjukkan bahwa banyak perempuan pada usia 7 sampai dengan 24 tahun yang memiliki pendidikan rendah atau bahkan tidak bersekolah. Salah satu penyebab perempuan di Kabupaten Nias memiliki tingkat pendidikan yang rendah karena orangtua 
banyak yang menikahkan anaknya disaat mereka seharusnya masih sekolah. Pernikahan mengambil hak mereka mendapatkan pendidikan tinggi. Faktor berikutnya adalah budaya patriarki Nias yang sekaligus berhubungan dengan jenis kelamin. Ada perbedaan peran antara laki-laki dengan perempuan di Nias. Dimana laki-laki mejadi seorang kepala, mendominasi, dan berkuasa. Sedangkan perempuan hanya dianggap sebagai pembantu laki-laki, tidak banyak berperan dalam kegiatan sosial kemasyarakatan maupun dalam keluarga, dan tidak sedikit yang mengalami kekerasan. Faktor lain adalah harga diri. Pernikahan adat Nias menjadikan mahar yang diberikan laki-laki kepada perempuan dimaknai sebagai "barang belian". Perempuan yang telah menikah dianggap telah menjadi hak milik suaminya yang bisa diperlakukan sekehendak hati sang suami. Hal tersebut yang menjadikan perempuan tidak memiliki harga diri. Faktor terakhir adalah situasi dimana perempuan Nias tidak dapat menggugat budayanya. Perempuan hanya bisa diam berhadapan dengan budaya yang dianggap tidak menguntungkan bagi dirinya karena takut dikeluarkan dari bagian anggota masyarakat tersebut.

Setelah mengetahui faktor-faktor yang mempengaruhi asertivitas perempuan di Kabupaten Nias, lalu apa yang bisa dilakukan dalam meningkatkan asertivitas mereka? Dalam hal ini penulis menyarankan bagi penulis berikutnya membuat penelitian yang mengkaji hal tersebut, karena belum pernah ada penelitian yang membahas mengenai asertivitas perempuan di Kabupaten Nias. Harapannya, kajian ini dapat menjadi bahan acuan dalam meneliti mengenai asertivitas perempuan di Kabupaten Nias selanjutnya.

\section{DAFTAR PUSTAKA}

Alberti, Robert, \& Emmons, Michael. 2002. Your Perfect Right. Penerjemah Buditjahya. Jakarta: PT.Elex Media Komputindo.

Ames, Daniel. 2009. Pushing up to a point: Assertiveness and effectiveness in leadership and interpersonal dynamics. Reseach in Organizational Behavior, Vol. 29, 111133.

Andayani, Friska Tri, \& Mardianto. 2015. Perbedaan asertivitas antara mahasiswa etnis Minang dan etnis batak. Jurnal RAP UNP, Vol. 6(1), 33-34.

Yesyca, M., Lase, F.J., \& Anggraini, N. 2018. Mapping interpersonal violence against women in the District of Nias, 2009-2016. Jurnal Masyarakat, Kebudayan dan Politik, Vol 31 (1), 24-35. 
Barrios, Yasmin V, et.al. 2015. Association of childhood physical and sexual abuse with intimate partner violence, poor general health and depressive symptoms among pregnant women. Plos One, 10(1), 1-18.

BPS Kabupaten Nias. 2018. Stasistik Kesejahteraan Rakyat Kabupaten Nias 2018. Nias: BPS Kabupaten Nias.

BPS Kabupaten Nias. 2018. Stasistik Kesejahteraan Rakyat Kabupaten Nias Selatan2018. Nias : BPS Kabupaten Nias Selatan.

BPS_Kabupaten Nias. 2018. Stasistik Kesejahteraan Rakyat Kabupaten Nias Utara 2018. Nias: BPS Kabupaten Nias Utara.

Firdaus, Gustaf. 2015. Hubungan antara harga diri dengan perilaku asertif pada mahasiswa Fakultas Psikologi UKSW. (Skripsi tidak diterbitkan). Universitas Kristen Satya Wacara, Salatiga.

Ge'e, H. 2017. Kedudukan perempuan dalam keluarga di masyarakat Nias. (Tesis, tidak diterbitkan). Universitas Kristen Satya Wacana, Salatiga.

Guruge, Sepali, et al. 2017. Intimate partner violence in the post- war context: Women's experiences and community leaders' perceptions in the Eastern Province of Sri Lanka. Plos One, 12(3), 1-16.

Irmayani, Tengku., Nurbani \& Bangun, Sabariah. 2015. Local genius dan implementasi pengarusutamaan gender pada pemerintahan kabupaten di Sumatera Utara. Mimbar, Vol. 31(2), 475-484.

Lase, Formas Juitan. 2018. Karakteristik Kekerasan Seksual terhadap Perempuan di Kabupaten Nias. Jurnal Inada Vol 1(1), 1- 25.

Novalia \& Dayakisni, Tri. 2013. Perilaku asertif dan kecenderungan menjadi korban bullying. Jurnal Ilmiah Psikologi Terapan, Vol 1(1), 172-178.

Nurhayati, Eti. 2016. Psikologi Perempuan: Dalam Berbagai Perspektif. Yogyakarta : Pustaka Pelajar.

Pongtuluran, Nalia Intan. 2014. Muatan-muatan Diskriminasi Gender yang Tersirat dalam Peraturan dan Kebijakan Pemerintah dan Swasta. Makalah NonSeminar. Depok: FISIP UI.

Rathus, S.A., \& Nevid, J.S. 1983. Adjustment and Growth: The Challenges of Life (2nd ed). New York: CBS College Publishing.

Susilawati, Dwi. 2016. Hubungan antara komunisai interpersonal dan asertivitas terhadap perilaku seks pranikah pada remaja: SMK Negeri 5 Samarinda Kalimantan Timur. Psikoborneo, Vol. 4(4), 688-701.

Syafira, Genti Aulia, \& Kustanti, Erin Ratna. (2017). Gambaran asertivitas pada perempuan yang pernah mengalami kekerasan dalam pacaran. Jurnal Empati, Vol. 6(1), 186-198.

Towned, Anni. 2007. Assertiveness and Diversity. New York : Pargrave Macmillan.

Zaluchu, Fotarisman. 2015. Tragedi Perempuan Nias, Sampai Kapan?", Nias Bangkit, 8 Mei, diakses tanggal 20 Maret 2018 dari $\underline{\text { http://nias- }}$ bangkit.com/2015/05/tragedi-perempuan-nias-sampai-kapan/ 
Zaluchu, F. 2016. Nasib Perempuan Nias. 21 April. Di akses tanggal 20 Maret 2018 dari https://kabarnias.com/kanal/perempuan-anak/6173-6173.

Ziaei, Shirin, et.al. 2016. Experiencing lifetime domestic violence: associations with mental health and stress among pregnant women in rural bangladesh: the minimat randomized trial. Plos One, 11(12), 1-14. 